\title{
Vivendo como parente: notas sobre a concepção de pessoa e a organização social apiaká
}

\author{
Giovana Acácia Tempesta \\ Doutora em Antropologia Social (Universidade de Brasília) \\ Fundação Nacional do Índio (Funai) \\ Brasília, DF, Brasil \\ giovana_tempesta@yahoo.com.br
}

\begin{abstract}
Resumo Neste ensaio apresentarei uma discussão sobre a articulação entre a concepção de pessoa e a organização social dos Apiaká, povo de língua tupi-guarani que habita tradicionalmente a área dos rios Juruena e Teles Pires, formadores do Tapajós. A partir de dados históricos e etnográficos, demonstrarei que, apesar dos efeitos negativos do contato, observa-se uma continuidade sociocultural que deve muito à vigência de um sistema social regional, que há muito tempo articula os Apiaká aos Kaiabi e aos Munduruku. Proponho que tal continuidade, que pode ser apreendida por meio da análise do código moral local, com foco nas acusações de feitiçaria, participa do esquema simbólico da "predação familiarizante" (Fausto, 2000; 2001).
\end{abstract}

Palavras-chave: Apiaká, organização social, concepção de pessoa, acusações de feitiçaria.

$\mathrm{N}$

ESTE ENSAIO PROPONHO ANALISAR um aspecto da relação entre a organização social e a concepção de pessoa apiaká, um povo de língua tupi-guarani que habita tradicionalmente a área dos rios Juruena e Teles Pires, formadores do Tapajós e divisas naturais entre os estados do Amazonas, do Mato Grosso e do Pará. ${ }^{1}$ Pretendo demonstrar que as acusações de feitiçaria e o código moral que elas exprimem podem iluminar a forma como os Apiaká elaboram a produção de pessoas e grupos sociais, que se assemelha em muitos pontos a outras economias simbólicas amazônicas (Fausto, 2000).

Vários antropólogos contemporâneos apontam que as sociedades amazônicas são orientadas para a produção de pessoas, não de bens, por oposição à lógica que rege as sociedades de mercado, e que concebem o interior como uma esfera segura, porém estéril; assim, os poderes criativos e transformativos devem ser obtidos no exterior, numa relação que frequentemente assume a forma de predação (Gow, 1991; Gow, 1997; McCallum, 1998; Overing, 1981; Overing, 1999; Overing \& Passes, 2000; Stolze Lima, 1986; Stolze Lima, 1995; Vilaça, 1992; Viveiros de Castro, 1986; Viveiros de Castro, 2002, entre outros).

Em sua tese sobre a guerra amazônica, explicada como um momento na dinâmica de reprodução social, Fausto afirma que os diversos processos de fabricação da pessoa visam conferir a ela singularidade, beleza, fertilidade, agência e capacidade de interagir com seres exteriores (espíritos, divindades, animais e inimigos); ${ }^{2}$ que o desenvolvimento das

1 Os dados apresentados foram reunidos durante a elaboração de minha tese de doutorado (Tempesta, 2009a; ver também Tempesta, 2009b).

20 termo "agência" (agency) tem a acepção de capacidade de ação, reflexão e sentimentos, conforme os trabalhos de M. Strathern e R. Wagner sobre povos na Melanésia e os antropólogos das Terras Baixas da América do Sul que neles se inspiraram para dar conta de 
capacidades reprodutivas da pessoa e do grupo depende de um excedente de agência, distribuído desigualmente entre humanos e não humanos, e que a mediação entre "nós" e "eles" é feita menos por objetos que por pessoas, partes de pessoas e qualidades subjetivas como nomes, almas e músicas (Fausto, 2000, p. 934). O autor argumenta que o efeito sociológico mais amplo das guerras e dos rituais antropofágicos a elas associados seria a constituição e a manutenção de amplas redes de amizade e hostilidade, espaços políticos formados pelo fluxo de corpos e bens imateriais efetivado pelo casamento e pela guerra: "genros e esposas obtidos à mínima distância; cativos, nomes, músicas, carne, cabeças e trofeus capturados a uma distância mediana. Este último fluxo é polarizado entre a alteridade mínima do afim real e a alteridade inassimilável do outro desconhecido" (Fausto, 2000, p. 948).

De modo complementar, Fausto critica a proposição teórico-metodológica de que a afinidade é o principal modelo de articulação entre interior e exterior do socius, divisando uma alternativa poderosa: o conceito de "predação familiarizante", um esquema de apropriação de alteridades que toma como modelo a filiação adotiva (da qual o xerimbabo é o principal protótipo), repousa sobre o princípio da predação ontológica e se expressa na guerra, no ritual, no xamanismo e no complexo da caça.

Fausto afirma que toda adoção é ambivalente e geralmente é esquematizada como uma relação paifilho, em que um não pode jamais neutralizar a potência subjetiva (fertilidade e capacidade produtiva) do outro; se isto ocorrer, o filho adotivo/cativo de guerra/animal domesticado perde sua função, que é justamente conferir um excedente de agência ao pai adotivo/matador/dono. A adoção mostra-se assim como relação assimétrica de controle, que necessariamente comporta riscos, especialmente o risco permanente de se transformar naquilo (naquele) que se quer controlar. De acordo com Fausto, a filiação adotiva consiste num caso particular de uma estrutura relacional mais ampla que articula predação e familiarização, afinidade e consanguinidade, exterior e interior; ela representa a transformação de uma relação de predação (real ou virtual) numa relação de controle e proteção (conversão de inimizade em familiaridade), tomando como modelo geral a passagem da afinidade para a consanguinidade (Fausto, 2000, p. 939).
Amparada em dados históricos e etnográficos, penso que o modelo apiaká de relação com Outros (brancos, forasteiros, afins reais e potenciais, animais, entes sobrenaturais etc.) se insere naquela estrutura relacional mais ampla, e pode ser categorizada como uma relação de adoção, conforme os termos propostos por Fausto. Os Apiaká parecem tentar sempre converter desconhecidos em familiares, sem deixar, contudo, de levar em conta os riscos implicados na passagem da afinidade para a consanguinidade.

O formato da organização sociopolítica apiaká contemporânea é a comunidade, que pode ser definida sumariamente como um conjunto de famílias extensas sustentado simbolicamente pela premissa de que todos os corresidentes são parentes e agem como tal. Do ponto de vista sociológico, a comunidade é composta por um agrupamento de casas habitadas por seções de famílias extensas; dispõe de escola, posto de saúde e um salão onde ocorrem reuniões de cunho político, festas e celebrações religiosas. A ética da cooperação e da moderação norteia o laborioso processo cotidiano de "fazer parentes", processo que se opõe simbolicamente às metamorfoses (a habilidade reprovável de virar bicho ${ }^{3}$ temporariamente, dominada apenas pelos pajés do mal). ${ }^{4}$

O modelo de socialidade apiaká participa de um padrão regional que foi descrito por Fausto (2000), em que se considera como parente aquele com quem se tem um vínculo genealógico e com o qual se observa a conduta apropriada; a relação com parentes é norteada pelo ideal de troca pacífica e partilha; desse modo, o "nós" é definido por meio de atos de generosidade, solidariedade e ausência de predação (Fausto, 2000, p. 948), em oposição à relação com os inimigos. Esse ideal tem como contrapartida a premissa Apiaká de que todas as pessoas podem virar bicho, uma vez que o avesso do corpo humano é animal (a imagem mais recorrente utilizada pelos indígenas é a da roupa: para virar bicho, basta despir a pele humana). $\mathrm{O}$ caso é que apenas algumas pessoas têm a habilidade de se transformar em anta, capivara, onça, macaco etc. de forma controlada para fazer mal aos corresidentes.

Ora, se todos podem virar bicho, há que ensinar cada corresidente a ser uma pessoa plena, isto é, deve-se incutir nele as habilidades propriamente sociais, para que se torne verdadeiramente um parente. O parentesco apiaká supõe assim uma moral estrita, num

fenômenos de sua própria área etnográfica (Overing e ex-alunos). "Agência" articula-se aos conceitos de relatedness (o sentimento de estar relacionado a outros, produzido por meio de ações cotidianas como a partilha, as dádivas alimentares, os resguardos, a socialização das crianças, que são criadas simultaneamente como parentes e como semelhantes, como descreve Gow, 1991) e de socialidade (uma forma ativa de criação e manutenção de relações sociais, que envolve as pessoas numa trama de interdependências mútuas). Tais antropólogos pensam a humanidade (humanity) como ideal moral, distinguindo-a da humanidade como espécie (humankind)

3 Bicho é a palavra que os Apiaká usam para se referir a "espírito" ou a ente "sobrenatural". As várias espécies de mamíferos que vivem na mata são chamadas de animais.

4 Utilizo o itálico para destacar os termos empregados pelos próprios Apiaká em suas narrativas. 
universo social que tem a animalidade/hostilidade/ inimizade como possibilidade iminente.

Para os Apiaká e para diversos povos indígenas amazônicos, a forma mais eficiente de "fazer um parente" é comer junto com ele. O valor da comensalidade para a produção da pessoa, do parentesco e da socialidade na Amazônia indígena foi ressaltado por vários antropólogos (Gow, 1991; Overing \& Passes, 2000; Vilaça, 1992, entre outros). Ao pensar a comensalidade (associada à caça e ao interior) e a antropofagia (associada à guerra e ao exterior) como diferentes modalidades de constituição da identidade e da diferença, Fausto (2002) afirmou que deixar de comer como e com alguém é recusar o aparentamento, tal recusa equivalendo a se colocar na posição de inimigo. Nesse sentido, o parentesco surge como a questão ética central na Amazônia e predomina sobre a relação entre humanos e animais - categorias que não são separadas por uma barreira ontológica.

De acordo com a cosmologia apiaká, as metamorfoses atestam a capacidade de agência partilhada por todos os seres do cosmos, um cosmos caracterizado por um potencial transformacional generalizado. Pessoas que viram bichos quando desejam fazer mal a um corresidente; peixes que se transformam definitivamente em pessoas; corpos de índios inimigos que, cozidos, tornam-se insetos; pessoas que se tornam corpos celestes devido a seu comportamento impróprio; sobrenaturais que assumem a forma humana para obter um alimento apreciado pelos Apiaká - tudo isso indica que o corpo é pensado/ vivido como um envelope físico circunstancial, uma "roupa" que pode ser temporariamente abandonada ou perdida definitivamente (Tempesta, 2009, p. 208). Dessa forma, assim como ocorre entre vários outros povos indígenas, "se tudo pode ser humano, então nada é humano inequivocamente" (Viveiros de Castro, 2002, p. 377). O maior problema experimentado pelos Apiaká é, com efeito, circunscrever a forma humana à conduta e ao espaço que lhe são adequados, de modo a impedir que o vínculo de parentesco venha a se dissipar no horizonte da alteridade - o que, do ponto de vista dos humanos, denota a morte.
No esquema conceitual apiaká, o espaço adequado à plena realização de pessoas/parentes é a comunidade, e o estilo de vida que nela prevalece se distingue tanto do estilo de vida dos índios bravos quanto do estilo de vida dos brancos urbanos. ${ }^{5}$ A aldeia opõe-se ao fundo do rio e à floresta, lugares que encerram muitos mistérios e perigos para as pessoas e que abrigam seres monstruosos, daí o zelo demonstrado pelos mais velhos em relação às crianças e às mulheres que saem sozinhas dos limites da aldeia, e o desejo de possuir cães de guarda para proteger as casas. O mundo subaquático é concebido como uma réplica do mundo humano, com roçados e casas; os temidos seres encantados que aí habitam, designadamente a mãe d'água (em apiaká: ajáng), ${ }^{6}$ a sucuriju (mosahúa, a dona dos peixes) e os botos (piraputóa), por vezes tentam seduzir as pessoas; quando conseguem capturar a "sombra" (sinônimo imperfeito de espírito e alma) de uma pessoa, seu corpo pode definhar até a morte (Tempesta, 2009, p. 124).

Bem, de que maneira essa concepção sobre a pessoa e os demais seres do cosmos se articula à organização social apiaká? Em que medida tal concepção exprime uma continuidade histórico-estrutural e a especificidade sociocultural do povo?

Para tentar responder a estas questões, voltemonos para a relação de afinidade, que ocupa um papel complexo nas filosofias tupis, articulando-se ao padrão de residência e à organização política de modo singular. De acordo com Viveiros de Castro, a célebre equação tupi entre inimigo, cativo de guerra e cunhado (tovaja) apontaria para o valor político da uxorilocalidade. ${ }^{7}$ Entre os tupis e também entre os povos guianeses, essa regra de residência integraria uma "estratégia geral de endogamia, que inflete ou cria soluções residenciais a posteriori - sempre a partir de um 'atrator uxorilocal de base",, do qual se pode escapar (Viveiros de Castro, 1986, p. 686).

A uxorilocalidade tupi operaria, pois, a abertura do sistema de parentesco ao evento, e responderia em parte pela instabilidade e pela frouxidão morfológica das aldeias. No passado, o líder-guerreiro Tupinambá era antes de tudo um sogro e um chefe de maloca,

5 A aldeia apiaká e seu entorno imediato compõem o único espaço concebido como propriamente social e adequado para os humanos, similar àquilo que P. Gow (1991) escreveu sobre os povos nativos do baixo Urubamba (Amazônia peruana).

6 Anhanga é uma espécie de demônio da tradição tupi-guarani e o espírito canibal associado aos mortos dos Tupinambá antigos (Métraux, 1979, p. 56). Para vários povos tupi-guaranis contemporâneos, anhanga é o espectro do morto (cf. Viveiros de Castro, 1986, p. 255; ver especialmente o anhang Kagwahiv em Kracke, 1978, e o anchunga Tapirapé em Wagley, 1988).

7 Complementarmente, lembro que Lévi-Strauss escreveu sobre a instituição do cunhadio entre os Nambiquara (família linguística isolada), que the chamara a atenção quando do primeiro encontro entre dois subgrupos que se fundiram posteriormente (Lévi-Strauss, 1943). Para o autor, a singularidade do evento residia no fato de que o idioma escolhido para o tratamento recíproco entre os homens não tenha sido o da fraternidade, mas o do cunhadio, sendo que os vocativos empregados exprimiam uma relação entre um homem e seus aliados colaterais sem que tivesse ocorrido casamento. Com base neste exemplo etnográfico e em textos de viajantes sobre os tupis quinhentistas, Lévi-Strauss chega à conclusão de que, entre os ameríndios, a relação entre cunhados extravasa o domínio do parentesco, consistindo num modo de assegurar intercasamentos e assim amalgamar grupos sociais ou familiares previamente heterogêneos em uma nova unidade homogênea. 
e as aldeias eram agregados de malocas fundados na afinidade e voltados para a guerra, sendo que o prestígio, derivado do número de inimigos mortos em combate, facultava aos homens escapar à residência uxorilocal, reter os filhos homens, atrair genros, ter casamentos poligâmicos e fundar novas malocas (Viveiros de Castro, 1986, p. 689).

Como demonstrei em outro lugar (Tempesta, 2009), também entre os Apiaká a uxorilocalidade é uma expectativa à qual o homem pode se furtar, especialmente quando se trata de homem de prestígio. Geralmente, os homens influentes Apiaká conseguem reter filhos e atrair genros sem causar descontentamento à família destes, pois se sabe que ele terá acesso a bens industrializados e poderá se tornar igualmente um homem influente, o que acabará beneficiando, em alguma medida, sua família de origem. Porém, quando não pode se furtar à residência uxorilocal, o novo genro/cunhado deve se resignar à mudança de casa e/ou de aldeia e aprender a ser parente dos consanguíneos imediatos da esposa. Sua conduta deve ser exemplar e, ainda que se comporte exemplarmente, será o alvo preferencial das fofocas. O mesmo ocorre quando é a mulher que se muda para a aldeia do marido; em casos extremos, ela se isola socialmente e se torna o alvo central das fofocas na aldeia.

O problema é que não se pode saber de antemão como um genro/cunhado (real ou potencial) vai se comportar com os novos parentes. Para os Apiaká, os parentes afins (que podem ser consanguíneos distantes, forasteiros ou pessoas de outra etnia conhecidas de longa data) são o símbolo máximo da ambivalência. Não se conhecem bem suas intenções, sentimentos, opiniões e habilidades, mas em princípio se espera que aquele que ingressa na família pela via do casamento seja generoso, respeitador e que cuide dos novos parentes. A única coisa que se pode fazer é tentar imprimir nos parentes afins, cotidianamente, as qualidades propriamente sociais que o transformarão em uma pessoa verdadeira, inviabilizando ou ao menos dificultando sua atuação como bicho ou como inimigo. A nova família age, pois, no sentido de "domesticar" o parente afim. $\mathrm{Na}$ ausência de rituais específicos e de instituições de controle mais rígidas, o mecanismo que permite controlar tal processo é a fofoca.

Com efeito, do ponto de vista da organização social, a fofoca, além de comunicar o código moral dentro da aldeia, com o objetivo de produzir parentes verdadeiros, também comunica sentimentos e opiniões em relação a Outros com quem os Apiaká convivem intimamente - os Kaiabi (língua tupiguarani) e os Munduruku (língua do tronco Tupi), com os quais mantêm relações de hostilidade mais ou menos velada e alianças mais ou menos duradouras, além de descendentes de arigós. ${ }^{8}$

Propus que os Apiaká, os Kaiabi e os Munduruku que vivem na área dos formadores do Tapajós compõem um "sistema social regional" (Heckenberger, 2001, p. 91), um conjunto de redes de interação e aliança em que se trocavam no passado - e ainda se trocam hoje em dia - pessoas, objetos e outros signos relacionais, e graças ao qual os diversos grupos locais Apiaká, Kaiabi e Munduruku puderam gozar de relativa autonomia diante do colonizador. Tal sistema parece ter proporcionado certo grau de equilíbrio interétnico desde o século XIX, assegurando as condições de sobrevivência (física e política) do povo Apiaká (Tempesta, 2009, p. 90).

Vejamos se a hipótese aqui apresentada tem respaldo histórico. Antes da expansão da frente da borracha para a Amazônia meridional, em meados do século XIX, os Apiaká formavam um povo numeroso, guerreiro e antropófago, que habitava a área delimitada pelos rios Arinos e Juruena. A extensão de seu território era determinada pela empresa guerreira, pela coleta de pedras para seus machados e de taquaras para fabricar flechas; eles percorriam vastas extensões no encalço de seus inimigos tradicionais, os Matanawi (não identificados), os Tapayúna (ou beiço-de-pau, do tronco macro-jê), os Munduruku e os Parabi-tatá (possível subgrupo Apiaká), demonstrando grande capacidade de mobilização para a guerra (Guimarães, 1865, p. 317; Nimuendaju, 1963a; 1963b). As belas tatuagens faciais, a marca distintiva do povo, exprimiam as "proezas e valentias nos combates com inimigos", bem como a participação nos ritos antropofágicos decorrentes das guerras (Castelnau, 2000; Guimarães, 1865).

Menéndez demonstrou que a área entre os rios Madeira e Tapajós caracteriza-se por uma alta densidade demográfica indígena desde o século XVII, sendo habitada por numerosos povos tupis e alguns povos macro-jês altamente móveis, que constituíam uma rede de relações intrincada por meio das guerras e das trocas (Menéndez, 1981/1982; 1992). É possível que tais povos não formassem unidades sociais discretas e duradouras, a exemplo dos Tupinambá quinhentistas, cujas aldeias da costa compunham um conjunto informe de grupos locais circunvizinhos, que não estava sujeito a uma autoridade comum nem tinha fronteiras rígidas (Fausto, 1992, p. 384). Fausto propõe que

A inimizade recíproca distinguia grupos de aldeias aliadas, que operavam segundo uma estrutura de tipo 'rede': as aldeias, unidas uma a uma, formavam um ‘conjunto multicomunitário' capaz de se expandir e 
se contrair conforme os jogos da aliança e da guerra. Os limites dessas unidades não são palpáveis nem definitivos: um dia poder-se-ia estar de um lado, no dia seguinte do outro - inimigos (e cunhados) eram justamente tobajara: 'os do outro lado', como sugere a etimologia mais provável do termo. (Fausto, 1992, p. 384; ênfase adicionada)

Significativamente, a narrativa-mestra apiaká, resumida a seguir, a respeito do processo de "amansamento" vivido pelo povo na virada para o século XX, no contexto da consolidação da frente extrativista da borracha na região dos rios formadores do Tapajós, trata de um cunhado branco que frustrou as expectativas de seus parentes e, assim, tornou-se inimigo:

Tinha uma índia Apiaká, a mulher do Paulo Corrêa, era ela que atiçava o pessoal dele para matar Apiaká: 'Pode matar Apiaká, Apiaká não presta.' Aí o pessoal sentava o pau, lá na Barra. Aí os Apiaká fugiram da Barra, foram para o São Tomé, foram fazer a aldeia Apiakatuba: 'Aqui é nosso lugar, Apiakatuba', se escondendo por causa daquele pessoal. Aí foi indo, até que terminou essa briga deles, os Apiaká ficaram mansos, acabou o medo dos brancos. [...] Eles pegaram a cabeça do Paulo Corrêa lá na Barra mesmo, o guaxeba dele, branco mesmo, entregou para os Apiaká: 'Aqui a cabeça do seu cunhado; ele matava um monte de parente de vocês, agora vocês levam para a aldeia de vocês.' Aí eles foram por terra de novo; atravessaram o rio Bararati e o Ximari, na banda do Amazonas. Quando chegaram na boca do São Tomé, atravessaram para esse lado do Pontal. Aí pegaram a estrada deles e vieram embora. Chegaram na aldeia, falaram: 'Olha a cabeça do Paulo Corrêa. O amigo dele mesmo entregou a cabeça para fazer festa. Então nós trouxemos.' Aí pintaram a cabeça dele de urucum, botaram urucum no buraco dos olhos dele, riscaram tudo, passaram jenipapo, ficou pretinho, tornaram a riscar do outro lado, aqueles riscos no rosto, ficou diferente. 'Você conhece aquele cara que matava nossos parentes?' 'Não.' 'Olha aí ele', o capitão dizia. Era assim. Mas era festa direto, vários dias. Dizem que ele matava gente demais, até branco ele matava. (Pedrinho Kamassori, aldeia Mayrob, 2007)

O seringalista e coletor de impostos Paulo Corrêa tornou-se famoso na área de confluência dos rios
Juruena e Teles Pires, nos primeiros anos do século XX, por seus atos de violência contra índios e não índios (Brasil, 1910; Pyrineus de Sousa, 1916; Rondon, 1915, 1916). De acordo com um documento de 1936 , foi o sucessor de Paulo Corrêa, o seringalista José Sotero Barreto, que se casou com uma mulher Apiaká. Um delegado do Serviço de Proteção aos Índios assim se reportou aos superiores: "as perseguições e destroços aos índios Apiacás pelas forças fiscaes do Estado distam já de muitos annos" e "Para pôr em relevo a cordialidade com que este exemplar exactor [José Sotero Barreto] agia na zona com os Apiacás, basta dizer que se consorciou com uma Apiacá e tem os seus filhos cursando as academias de direito e medicina, em Belém” (Serviço de Proteção aos Índios. Documento enviado por Antonio Antero Paes de Barros, delegado especial do Norte, para Carlos Murtinho, presidente do Grêmio Precursor Mattogrossense do Instituto Rondon, em 16 de março de 1936).

Verifica-se que a personalidade ou o comportamento efetivo do cunhado não importa tanto quanto sua posição na estrutura de parentesco. A mensagem transmitida pela narrativa consiste na ambivalência do parente afim: um cunhado tanto pode cuidar, proteger, colaborar nas atividades diárias, oferecer apoio político e econômico para a família da esposa quanto desrespeitá-la, desprezá-la e, no limite, destruí-la.

$\mathrm{Na}$ narrativa transcrita, a própria identidade social de Paulo Corrêa é colocada em xeque: um patrão branco que se torna afim e age como onça, desconsiderando o ideal de generosidade e ajuda mútua implicado na relação matrimonial e devorando as pessoas, é morto e festejado como um inimigo. Os Apiaká quase foram dizimados ${ }^{9} \mathrm{e}$, sem dúvida, se transformaram em termos sociais e culturais, mas continuam acreditando que o inimigo é indispensável para a perpetuação do grupo - não um inimigo distante, inescrutável, e sim um inimigo próximo, domesticado (um xerimbabo?).

Os Apiaká abandonaram as guerras de vingança há muito tempo, mas isto não significa que deixaram de necessitar de seres outros para se reproduzirem como grupo. A oposição inimigo-parente permanece ocupando posição central em sua cosmologia. Neste sentido, a forma como estabeleceram relações de parentesco no último século exprime uma reflexão sobre as possibilidades e os riscos de transformar Outros (designadamente Munduruku, Kokama, ${ }^{10}$

9 Os Apiaká foram considerados extintos por d. Ribeiro nos anos 1950, com base num relatório da Comissão Rondon escrito pelo capitão Manoel Teophilo Costa Pinheiro (Ribeiro, 2002, p. 263). Em 1912, o capitão encontrara apenas 32 Apiaká no lugar chamado Barra de São Manoel (AM), sobreviventes dos ataques promovidos por coletores de impostos mato-grossenses. No entanto, outra seção do povo havia migrado anteriormente para as imediações da Missão Franciscana do Cururu (PA) e um terceiro segmento retornara para as margens do rio São Tomé (MT), uma região distante da rota comercial Cuiabá-Belém. Após os massacres, os Apiaká foram vítimas de epidemias de sarampo e outras doenças infectocontagiosas contra as quais não tinham imunidade.

10 o kokama não é uma língua classificável geneticamente, embora o tupinambá seja um dos idiomas que a compõem, ao lado do pano, do arawak e do espanhol. 
Sateré-mawé, ${ }^{11}$ Kaiabi e arigós) em parentes (e também consanguíneos distantes em afins), bem como um desejo de casar à boa distância.

A formação da primeira comunidade apiaká no rio dos Peixes, nos anos 1960, atesta esse desejo. Em meados do século XX, os Apiaká abandonaram as aldeias às margens do Anipiri (PA) e se dispersaram pelo baixo curso do rio Juruena e pelo cursos baixo e médio do rio Teles Pires, onde continuaram trabalhando na indústria da borracha, que conheceu um segundo momento de apogeu durante a Segunda Guerra Mundial. Naquela época, alguns Apiaká conheceram o missionário jesuíta João Dornstauder, ligado à Missão Anchieta, que se dedicava à pacificação dos Rikbaktsa (tronco macro-jê) no médio Juruena. Simultaneamente, o missionário tentava fixar os Kaiabi no rio dos Peixes (MT). ${ }^{12}$ Pouco tempo depois de fundada a aldeia Kaiabi chamada Tatuí, na margem esquerda do rio dos Peixes, ele convidou algumas famílias apiaká para se mudarem para lá. No início dos anos 1970, os Apiaká que estavam em Tatuí decidiram se separar dos Kaiabi e fundaram uma aldeia própria, chamada Nova Esperança, na outra margem do rio dos Peixes, a poucos quilômetros de distância de Tatuí. Significativamente, os Apiaká não se casaram com os Kaiabi de Tatuí (com raras exceções), mas preferiram recrutar cônjuges Munduruku na Missão Cururu.

Todavia, as famílias apiaká que se mudaram para a aldeia Nova Esperança jamais deixaram de visitar os parentes que permaneceram na Missão Cururu; partindo do rio dos Peixes de canoa, alcançavam o Arinos, desciam o Juruena, chegavam ao Tapajós e daí enveredavam pelo rio Cururu. As viagens levavam meses e por vezes resultavam em casamentos e migrações não apenas do cônjuge como também de grande parte de sua família extensa para o rio dos Peixes.

A decadência da aldeia Nova Esperança condensa o valor político da generosidade para os Apiaká, pois eles afirmam que a falta de generosidade ou, de uma maneira mais ampla, a incapacidade de agir como parente demonstrada pelo primeiro cacique determinou a desagregação da aldeia, em 1979. Por outro lado, caciques apiaká que dão demonstrações reiteradas de generosidade para visitantes Kaiabi e Munduruku de aldeias vizinhas e também para os não índios (funcionários do Estado que frequentam a aldeia) são reputados bons e passam a gozar de prestígio dentro e fora de sua comunidade. Famílias Kaiabi e Munduruku podem mesmo se mudar para as aldeias Apiaká devido à boa fama do cacique, engrossando assim o rol de seus apoiadores (reais e potenciais). Pode-se afirmar que, atualmente, o fato de haver um número substancial de Kaiabi vivendo em aldeias apiaká (e, inversamente, um número substancial de Apiaká vivendo em aldeias kaiabi e munduruku) exprime a vigência de vínculos sociopolíticos fortes entre os três povos, combinados a sentimentos de desconfiança e rivalidade.

Essa relação de interdependência, historicamente constituída, encerra um aspecto simbólico que aproxima os Apiaká de outros povos amazônicos, qual seja: a alteridade é concebida como ambivalente e absolutamente necessária para a reprodução do grupo.

Observemos agora a dinâmica da fofoca e das acusações de feitiçaria entre os Apiaká; para tanto, tomarei como contraponto um artigo de Lamphere (1971) que versa sobre a relação entre os conceitos de cooperação e autonomia, a fofoca e a feitiçaria entre os Navaho (Estados Unidos). Com base na distinção analítica entre sistema social e sistema cultural, Lamphere afirma que a sociedade Navaho é uma sociedade igualitária, em que os grupos domésticos são ligados por meio de conjuntos egocentrados de parentes primários e secundários, que são potenciais colaboradores. Esse sistema social aberto e flexível corresponde a um sistema cultural por meio do qual os Navaho interpretam e organizam o comportamento no cotidiano (Lamphere, 1971, p. 91). Articulados, a obrigação moral difusa de ajudar e cuidar, de um lado, e os conceitos de consenso e de autonomia pessoal, de outro, têm impacto contundente no recrutamento da colaboração em atividades diárias, sendo este um elemento importante na manutenção dos vínculos dentro de um grupo de residência e também entre grupos de residência distintos.

Neste sentido, a ética da cooperação, cifrada "em negativo" pela fofoca e pelas acusações de feitiçaria, fornece o gabarito do comportamento cotidiano, permitindo classificar de modo inequívoco cada atitude como adequada ou inadequada. $\mathrm{Na}$ dinâmica de comunicação composta pela fofoca e pelas acusações de feitiçaria, atos concretos são qualificados como "vis", "loucos", "ciumentos", "mesquinhos" etc.; tais conceitos, contudo, não são empregados no sentido de descobrir se uma determinada pessoa de fato agiu de uma certa maneira, mas sim no sentido de comunicar a inadequação da ação em relação a um código. Dessa forma, tais conceitos se tornam parte de um sistema cultural compartilhado, e novos comportamentos e ideias continuam sendo classificados a partir do código moral tradicional; assim, de acordo com a autora, o sistema cultural exibe uma maior estabilidade e uniformidade em comparação com o sistema social (Lamphere, 1971, p. 102).

Assim como os Navaho, os Apiaká valorizam sobremaneira a autonomia pessoal, o comportamento

11 Sateré-mawé é uma língua do tronco Tupi.

12 O rio dos Peixes é afluente do Arinos e se situa no interior do território histórico apiaká. 
colaborativo e a generosidade (especialmente no que se refere a alimentos), e as decisões coletivas geralmente se sustentam no consenso; cultivam ainda os ideais de pacifismo e hospitalidade. A fofoca, aqui definida como uma modalidade de fala privada (por oposição à fala pública do salão) associada às mulheres, é o dispositivo que põe em funcionamento o "sistema cultural compartilhado" pelos Apiaká. A fofoca é o principal veículo das mensagens sobre a adequação ou inadequação das ações das pessoas aos critérios de gênero e idade que devem reger o comportamento, sobre a disposição dos corresidentes para ajudar nos trabalhos coletivos, sobre as virtudes ou defeitos do cacique, sobre a qualidade e a quantidade das dádivas cotidianas, sobre as características das aldeias vizinhas, sobre os bens industrializados que algumas pessoas adquirem.

Sovinar um alimento ou um objeto é o único motivo legítimo para castigar as crianças pequenas. Quando se trata de adultos, a mesquinharia contumaz, especialmente a mesquinharia alimentar, é índice contundente de má índole, podendo ainda exprimir capacidades maléficas, inclusive a capacidade nefasta de virar bicho. De outro modo, quando um adulto recusa um alimento ou objeto para um corresidente porque não dispõe dele em quantidade normalmente começa a temer por sua saúde; se se sente mal algumas horas ou dias após o evento, logo desconfiará de feitiço, e comentários neste sentido começarão a circular.

Por seu turno, um bom cacique é um homem extremamente generoso, que recebe bem os visitantes e exalta as qualidades de sua aldeia; um bom cacique não ordena, e sim convida, dá o exemplo, explica e atua como intermediário em situações que exigem a obtenção da unanimidade de opiniões. Quando o cacique não age como deveria, o dispositivo da fofoca é acionado; a pressão pode se tornar insuportável a ponto de ele renunciar ao posto.

O comportamento de meninos e meninas é tema recorrente nas conversas informais cotidianas. Bons pescadores e caçadores são elogiados, meninos preguiçosos e bagunceiros são criticados; meninas que ajudam sua mãe nos afazeres domésticos são elogiadas, as namoradeiras são criticadas.

É preciso dizer, ainda, que, sempre que uma pessoa adoece sem motivo aparente, ou então quando um animal de estimação ou uma pessoa morre de forma inesperada, pensa-se logo em feitiçaria. De um modo geral, as doenças (karuára) e a morte são atribuídas à ação humana. Os Apiaká acreditam que as palavras, os pensamentos e os sentimentos das pessoas têm um peso crucial no destino de cada um. Dessa maneira, a fofoca também toma parte importante na configuração de diagnósticos de doenças.

Assim como a crença zande em bruxaria, a crença apiaká em feitiçaria consiste numa chave explicativa a posteriori de infortúnios, expressando "um sistema de valores que regula a conduta humana" (Evans-Pritchard, 1978, p. 56) e fornecendo um idioma para falar sobre comportamentos socialmente condenáveis. Nesse sentido, se ocorre um fato extraordinário, como uma capivara pisando sobre cacos de vidro no terreiro de uma casa e, algumas horas depois, chega ao posto de saúde da aldeia uma pessoa com os pés estranhamente cortados, sem que tenha passado pelo terreiro onde ocorreu o incidente, os dois eventos são postos em relação de causalidade, e o nome do suposto culpado é rapidamente proferido à boca pequena ou em tom jocoso. As pessoas vão procurar saber o que o suspeito estava fazendo àquela hora e, se não descobrirem, sua culpa ficará comprovada.

É curioso que os Apiaká equacionem o pajé do bem ao forasteiro (socialmente distante) e o pajé do mal ao parente/corresidente (socialmente próximo). Sempre que descobrem que um corresidente está virando bicho, os Apiaká recorrem a pajés de aldeias distantes, com quem mantêm relações simplesmente cordiais, por cujo serviço pagam altos valores. A fofoca surge então como um mecanismo importante para identificar os pajés do mal dentro da aldeia e para avaliar a atuação dos pajés do bem.

Este não é um tema sobre o qual os Apiaká falam espontaneamente com forasteiros. Durante minha pesquisa de campo, quando eu interrogava alguém diretamente sobre o assunto, recebia invariavelmente a resposta taxativa: "Sobre gente que vira bicho eu não sei falar, eu não viro bicho!", o mesmo tipo de reação que Evans-Pritchard percebeu entre os Azande quando os interrogava sobre bruxaria (Evans-Pritchard, 1978, p. 49), e que explicita uma ênfase nos aspectos moral e utilitário do conhecimento: "saber falar sobre", conhecer, implica sempre um "saber-fazer" avaliado de acordo com rígidos parâmetros morais; falar sobre aquilo que não se sabe por experiência própria seria considerado uma leviandade (Tempesta, 2009, p. 204).

As acusações de feitiçaria, veiculadas sob a forma de histórias de transformação temporária de gente em animal, condensam o idioma da violência e da hostilidade, elementos que não são totalmente suprimidos pela ética da generosidade e do pacifismo promovida pelos caciques e demais pessoas influentes das aldeias.

A premissa de que as pessoas podem virar bicho e o código moral implicado nas acusações de feitiçaria apontam, pois, para a potencialidade animal da pessoa e a instabilidade simbólica da condição humana. A crença em metamorfoses temporárias com propósitos nefastos é uma maneira de afirmar que a humanidade é um estado a ser conquistado (e não uma condição imutável); quem falha nesse processo ou deliberadamente o recusa está, portanto, deixando de ser humano e será classificado alternativamente como bicho ou inimigo. 
Pode-se concluir que, entre os Apiaká, a fofoca é o contexto enunciativo do xamanismo, colocado a serviço da fabricação de pessoas e relações sociais. Trata-se, enfim, de uma epistemologia, uma teoria nativa do conhecimento sobre a pessoa, o mundo so- cial e o mundo natural, que não se separa do código moral, que encontra paralelos em vários outros povos indígenas amazônicos e que notavelmente resistiu a um processo de dispersão territorial, mudança social e catequização.

\section{Referências}

BRASIL, Raymundo Pereira. Os sertões do rio Tapajós. Pará: Secção de Obras d'A Província do Pará, 1910.

CASTELNAU, Francis de. Expedição às regiões centrais da América do Sul. Belo Horizonte/Rio de Janeiro: Itatiaia, 2000.

EVANS-PRITCHARD, E. E. Bruxaria, oráculos e magia entre os Azande. Rio de Janeiro: Jorge Zahar, [1937]1978.

GOW, Peter. Of Mixed blood: kinship and history in peruvian Amazonia. Oxford: Clarendon, 1991.

GOW, Peter. O parentesco como consciência humana: o caso dos Piro. Mana, v. 3, n. 2, p. 39-65, 1997.

FAUSTO, Carlos. Fragmentos de história e cultura tupinambá. Da etnologia como instrumento de conhecimento etno-histórico. In: CARNEIRO DA CUNHA, Manuela (Org.). História dos índios no Brasil. São Paulo: Companhia das Letras, 1992.

FAUSTO, Carlos. Of enemies and pets: warfare and shamanism in Amazonia. American Ethnologist, v. 26, n. 4, p. 933-956, 2000.

FAUSTO, Carlos. Inimigos fiéis: história, guerra e xamanismo na Amazônia. São Paulo: Ed. da USP, 2001.

FAUSTO, Carlos. Banquete de gente: comensalidade e canibalismo na Amazônia. Mana, v. 8, n. 2, p. 7-44, 2002. GUIMARÃES, José da Silva. Memórias sobre os usos, costumes e linguagem dos Apiaccás, e descobrimento de novas minas na Província de Mato Grosso. Revista Trimensal de História e Geografia, Jornal do Instituto Histórico e Geográfico Brasileiro, v. 6, p. 305-325, [1844]1865.

HECKENBERGER, Michael. Epidemias, índios bravos e brancos: contato cultural e etnogênese no Alto Xingu. In: FRANCHETTO, Bruna; HECKENBERGER, Michael (Orgs.). Os povos do Alto Xingu. História e cultura. Rio de Janeiro: Ed. da UFRJ, 2001.

KRACKE, Waud. Force and persuasion. Leadership in an Amazonian Society. Chicago: The University of Chicago Press, 1978.

LAMPHERE, Louise. The Navaho cultural system: an analysis of concepts of cooperation and autonomy and their relation to gossip and witchcraft. In: BASSO, Keith; OPLER, Morris (Orgs.). Apachean culture history and ethnolog $\%$. Tucson, Arizona: Anthropological Papers of the University of Arizona, 1971, n. 21.

LÉVI-STRAUSS, Claude. The social use of kinship terms among Brazilian indians. American Anthropologist, v. 45, part 1, p. 398-409, 1943.
MCCALLUM, Cecilia. Alteridade e sociabilidade Kaxinauá: perspectivas de uma antropologia da vida diária. Revista Brasileira de Ciências Sociais, v. 13, n. 38, p. 127-36, 1998.

MENÉNDEZ, Miguel. Uma contribuição para a etnohistória da área Tapajós-Madeira. Revista do Museu Paulista, v. XXVIII, p. 289-388, 1981-1982.

MENÉNDEZ, Miguel. A área Madeira-Tapajós. Situação de contato e relações entre colonizador e indígenas. In: CARNEIRO DA CUNHA, Manuela (Org.). História dos índios no Brasil. São Paulo: Cia. das Letras, 1992.

MÉTRAUX, Alfred. A religião dos Tupinambá e suas relações com a das demais tribos tupi-guaranis. São Paulo: Editora Nacional/Edusp, 1979.

NIMUENDAJU, Curt. The Cayabi, Tapanyuna and Apiacá. In: STEWARD, J. (Ed.) Handbook of South American indians, v. 3: The tropical forest tribes. Washington: Smithsonian Institution, Bureau of American Ethnology, 1963a.

NIMUENDAJU, Curt. The Cawahib, Parintintin, and their neighbors. In: STEWARD, J. (Ed.). Handbook of South American indians. v. 3: The tropical forest tribes. Washington: Smithsonian Institution, Bureau of American Ethnology, 1963b.

OVERING, Joanna. Review article: Amazonian anthropology. Journal of Latin American Studies, v. 13, part 1, p. 151-65, 1981.

OVERING, Joanna. Elogio do cotidiano: a confiança e a arte da vida social em uma comunidade amazônica. Mana, v. 5, n. 1, p. 81-107, 1999.

OVERING, Joanna.; PASSES, A. (Orgs.). The anthropology of love and anger - the aesthetics of conviviality in Native Amazônia. London and New York: Routledge, 2000.

PYRINEUS DE SOUSA, Antonio. Relatório de exploração do rio Paranatinga e seu levantamento topográfico bem como dos rios São Manoel e Teles Pires. Commissão de Linhas Telegraphicas Estrategicas de Matto-Grosso ao Amazonas. Publicação n. 34, Anexo 2. Rio de Janeiro: Typographia Leuzinger, 1916.

RIBEIRO, Darcy. Os índios e a civilização: a integração das populações indígenas no Brasil moderno. Petrópolis: Vozes, 2002.

RONDON, Cândido Mariano da Silva. Relatório apresentado à Directoria Geral dos Telegraphos e à Divisão de Engenharia (G5) do Departamento de Guerra. Com- 
missão de Linhas Telegraphicas Estrategicas de Matto-Grosso ao Amazonas. Publicação n. 26, Anexos 1, 2 e 3, v. 3. Rio de Janeiro: Typographia Leuzinger, 1915.

RONDON, Cândido Mariano da Silva. Conferências realizadas nos dias 5, 7 e 9 de outubro de 1915 pelo Cel. Candido Mariano da Silva Rondon no Teatro Phenix do Rio de Janeiro sobre trabalhos da Expedição Roosevelt e da Commissão Telegraphica. Commissão de Linhas Telegraphicas Estrategicas de Matto-Grosso ao Amazonas. Publicação n. 42. Rio de Janeiro: Typographia Leuzinger, 1916.

SERVIÇO DE PROTEÇÃO AOS ÍNDIOS. Inspetoria Regional 6 (Cuiabá). Relatórios Microfilmados dos Postos Indígenas José Bezerra e Pedro Dantas, disponíveis no Museu do Índio/Funai.

STOLZE LIMA, Tânia. A vida social entre os Yudjá (índios Juruna). Elementos de sua ética alimentar. 1986. Dissertação (Mestrado em Antropologia) - Museu Nacional/ UFRJ, Rio de Janeiro, 1986.

STOLZE LIMA, Tânia. A parte do cauim. Etnografia Ju- runa. 1995. Tese (Doutorado em Antropologia) - Museu Nacional/UFRJ, Rio de Janeiro, 1995.

TEMPESTA, Giovana Acacia. Travessia de banzeiros. Historicidade e organização sociopolítica apiaká. 2009a. Tese (Doutorado em Antropologia) - Universidade de Brasília, Brasília, 2009a.

TEMPESTA, Giovana Acacia. Patrões, cunhados e onças. Os brancos no universo relacional apiaká. In: SMILJANIC, Maria Inês; PIMENTA, José Pimenta; BAINES, Stephen Grant (Orgs.). Faces da indianidade. Curitiba: Nexo Design, 2009b.

VILAÇA, Aparecida. Comendo como gente. Formas de canibalismo Wari'. Rio de Janeiro: Ed. da UFRJ, 1992.

VIVEIROS DE CASTRO, Eduardo. Araweté, os deuses canibais. Rio de Janeiro: Jorge Zahar, 1986.

VIVEIROS DE CASTRO, Eduardo. A inconstância da alma selvagem. São Paulo: Cosac \& Naify, 2002.

WAGLEY, Charles. Lágrimas de boas-vindas. Os índios Tapirapé do Brasil Central. Belo Horizonte: Itatiaia, 1988.

\title{
Living as a relative: notes on the conception of person and the social organization of the apiaká
}

\begin{abstract}
In this paper, I'll discuss how the Apiaká Indians person's conception articulates with their social organization. The Apiaká are a Tupi-Guarani speaking people that inhabit the region of the Tapajós River basin, in the southeastern Amazonia. The historic and ethnographic data presented show that, despite the devastating effects of the Amazonian rubber boom, there is a sociocultural continuity due to the regional social system which articulates Apiaká, Kaiabi Indians and Munduruku Indians. Such continuity, which integrates the "familiarizing predation" model (Fausto, 2000; 2001) may be apprehended through the analysis of the local morality and of the witchcraft accusations.
\end{abstract}

Key words: Apiaká indians, social organization, concept of the person, witchcraft accusations.

\section{Viviendo como pariente: notas sobre la concepción de persona y la organización social apiaká}

\begin{abstract}
Resumen
Este artículo examina la articulación entre la concepción de persona y la organización social de los indígenas Apiaká, un pueblo de lengua tupi-guarani que habita la región de la cuenca del río Tapajós, en Amazonía meridional. Hechando mano de informaciones históricas y etnográficas, intentaré demostrar que no obstante las consecuencias negativas de la colonización, se nota una continuidad sociocultural probablemente apoyada en un sistema social regional conformado por los indios Apiaká, Kaiabi e Munduruku. Esta continuidad, que integra el modelo de la "predación familiarizante" (Fausto, 2000; 2001), puede ser aprehendida por medio del examen de la moralidad local, a partir de las acusaciones de hechicería.
\end{abstract}

Palabras-clave: Apiaká, organización social, concepción de persona, acusaciones de hechicería. 